\title{
DAYA TETAS DAN LAMA MENETAS TELUR AYAM TOLAKI PADA MESIN TETAS DENGAN SUMBER PANAS YANG BERBEDA
}

\author{
La Ode Nafiu ${ }^{1 *}$, Muh. Rusdin ${ }^{1}$, dan Achmad Selamet Aku ${ }^{1}$ \\ ${ }^{1)}$ Fakultas Peternakan Universitas Halu Oleo, Kampus Hijau Bumi Tridharma \\ Anduonohu Kendari 93232 Telp. 0401- 3190791 Fax 0401- 3190791 \\ *e-mail ; ldnafiu@gmail.com
}

\begin{abstract}
ABSTRAK
Penelitian ini bertujuan untuk mengetahui daya tetas dan lama menetas telur ayam tolaki pada mesin tetas dengan sumber panas yang berbeda. Penelitian dilaksanakan selama 5 bulan di kandang pembibitan Fakultas Peternakan UHO. Ayam tolaki yang digunakan terdiri atas 5 ekor jantan dan 15 ekor betina umur sekitar 20 bulan. Perkawinan ayam dilakukan dengan cara IB. Parameter yang diamati adalah: fertilitas, daya hidup embrio, daya tetas, bobot tetas dan lama menetas. Hasil penelitian menujukkan: (1) rataan fertilitas telur ayam tolaki pada mesin tetas PL adalah 58,57\% dan mesin tetas PLM adalah 46,88\%, namun kedua mesin tetas secara statistik tidak berbeda nyata, (2) rataan DHE pada mesin tetas PL adalah 96,67\% dan mesin tetas PLM adalah $89,58 \%$, (3) rataan daya tetas pada mesin tetas PL adalah 45,61\% dan mesin tetas PLM adalah 64,81\%, (4) rataan bobot tetas, pada mesin tetas PL adalah 26,47 g, sedangkan mesin tetas PLM 26,96 g, dan (5) lama menetas telur pada mesin tetas PL adalah 21.05 hari dan PLM adalah 21,09 hari. Secara statistik, penggunaan mesin tetas dengan sumber panas berbeda tidak berpengaruh nyata terhadap semua parameter yang diamati.Mesin tetas dengan sumber panas berbeda tidak berpengaruh nyata terhadap fertilitas, DHE, daya tetas, bobot tetas dan lama menetas telur ayam tolaki. Untuk meningkatkan daya tetas direkomendasikan menggunakan mesin tetas dengan sumber panas kombinasi listrik dan lampu minyak.
\end{abstract}

Kata Kunci : Fertilitas, DHE, Fertilitas Lama Menetas, Mesin Tetas dan Ayam Tolaki.

\begin{abstract}
This study aims to determine the hatchability and long of hatching of tolaki chicken eggs in incubator with different heat sources. Research carried outfor 5month sin breeding cage Faculty of Animalscience Halu Oleo University. Chicken Tolaki used consisted of 5 males and 15 females aged approximately 20 months. Mating chicken is done by IB. Parameters measured were: fertility, embryoviability, hatchability, hatching weight and long hatch.The results showed: (1) the average fertility Tolaki chicken egg sin PL incubatoris $58.57 \%$ and PLM incubatoris $46.88 \%$, but both the incubator statistically was not significantly different, (2) the average of DHE in PL incubator is $96.67 \%$ and PLM incubator is $89.58 \%$, (3) the average hatchability in PL incubator is $45.61 \%$ and PLM incubatoris $64.81 \%$, (4) the average weight of hatching in PL incubatoris $26.47 \mathrm{~g}$, while the PLM incubator is $26.96 \mathrm{~g}$, and(5) long the eggs hatch in PL incubator is 21,05 days and PLM is21,09 days. Statistically, the use incubator with different heat source had no significant effecton all parameters were observed. Incubator with different heat source does not significantly on fertility, DHE, hatchability, hatching weight and length of hatching of Tolaki chicken eggs, Improving the hatchability is recommended to use incubator with a combination electric and oil lamps heat sources.
\end{abstract}

Key Words: Fertility, Embryoviability, Hatchability and Length of Hatching, and Tolaki Chicken. 


\section{PENDAHULUAN}

Ayam Tolaki adalah salah satu jenis ayam lokal Indonesia dan merupakan plasma nutfah asli Sulawesi Tenggara yang tersebar di beberapa wilayah di Kabupaten Konawe, Konawe Selatan dan Kabupaten Kolaka. Selain sebagai penghasil daging, ayam Tolaki dikenal memiliki potensi sebagai penghasil telur, baik telur konsumsi maupun untuk ditetaskan, karena produksi telurnya cukup tinggi. Ukuran dan bobot telurnya relatif kecil daripada ayam kampung (Nafiu $d k k$.,2009). Peternak ayam tolaki di daerah ini sangat terbatas, dan umumnya berada di wilayah yang masih bersentuhan langsung dengan kawasan hutan. Keterbatas peternak ayam tolaki juga disebabkan oleh penggunaannya lebih banyak berkaitan dengan tujuantujuan tertentu, misalnya sebagai ayam sabungan yang menggunakan taji, upacara adat, penyelesaian perselisihan keluarga/adat, atau pengobatan (Nafiu dan Rusdin, 2007). Selain itu sistem pemeliharaan ayam tolaki masih dilakukan secara ekstensif tradisonal, termasuk penetasan telur masih mengandalkan indu, sehingga produktivitasnya rendah. Sehubungan dengan hal tersebut maka perlu upaya peningkatan produksi dan produktivitas, antara lain melalui program penetasan. Penetasan telur unggas dapat dilakukan dengan dua cara yaitu penetasan alami dan penetasan buatan. Penetasan alami yaitu menetaskan telur dengan menggunakan induknya atau jenis unggas lain dan penetasan buatan yaitu dengan menggunakan mesin tetas. Penetasan alami kurang efektif dalam menetaskan telur karena satu induk hanya bisa mengerami sekitar 10 butir telur, sedangkan penetasan buatan mampu menetaskan jumlah telur dalam jumlah ratusan bahkan ribuan butir, tergantung kapasitas tampung mesin tetas (Kartasudjana, 2001). Penerapan teknologi penetasan telur pada usaha peternakan ayam lokal, termasuk ayam tolaki diharapkan dapat meningkatkan populasi ayam dalam waktu yang relatif cepat dan menjamin kontinuitas ketersediaan bibit. Hal ini disebabkan karena mesin tetas berfungsi sebagai penggati induk dalam penetasan telur untuk menghasilkan anakanak ayam. Keunggulan penerapan teknologi mesin tetas adalah menghilangkan periode mengeram pada induk, sehingga induk lebih produktif dan mampu menghasilkan telur lebih banyak selama hidupnya. Selain itu anak ayam dapat diproduksi dalam jumlah yang banyak pada waktu yang bersamaan dan kapasitas penetasan dapat diperbanyak sesuai dengan jumlah telur tetas yang siap ditetaskan.

Pada prinsipnya penetasan telur dengan mesin tetas adalah menyediakan lingkungan yang sesuai untuk perkembangan embrio (calon anak), yakni yakni meniru sifat-sifat alamiah induk ayam atau itik yang mengerami telur, yaitu menyesuaikan suhu. kelembaban dan membalik telur yang dierami (Subiharta dan Yuwana, 2012).

Mesin tetas yang umum digunakan peternak dengan skala usaha kecil di daerah pedesaan adalah mesin tetas sederhana dengan kapasitas terbatas. Sumber panas yang digunakan dari listrik atau lampu minyak. Namun demikian, dalam penerapannya mesin tetas dengan sumber panas listrik sangat tergantung dari PLN, sehingga ketika listrik padam, maka proses penetasan akan terganggu bahkan dapat menyebabkan kegagalan. Oleh karena itu, mesin tetas sederhana dengan sumber panas listrik perlu dimodifikasi menjadi mesin tetas kombinasi dengan sumber panas listrik dan lampu minyak 
sehingga meskipun listrik padam suhu dalam mesin tetas tetap stabil dan perkembangan embrio dalam telur tidak terganggu. Penelitian ini bertujuan untuk mengetahui daya tetas dan lama menetas telur ayam tolaki pada mesin tetas dengan sumber panas yang berbeda.

\section{METODE PENELITIAN}

\section{Waktu dan Tempat}

Penelitian ini dilaksanakan selama 5 bulan, bertempat di Kandang Pembibitan Laboratorium Lapangan Fakultas Pertanian Universitas Halu Oleo Kendari.

\section{Materi Penelitian}

\section{a. Mesin Tetas}

Mesin tetas yang digunakan dalam penelitian ini adalah (1) mesin tetas sederhana dengan sumber panas listrik dan, (2) mesin tetas dengan sumber panas kombinasi listrik dan lampu minyak. Kapasitas mesin tetas masingmasing 150 butir yang dibuat Kandang Pembibitan Laboratorium Lapangan Fakultas Pertanian Universitas Halu Oleo.Telur Telur yang digunakan dalam penelitian ini adalah telur ayam Tolaki sebanyak 180 butir yang dikumpulkan dari 26 ekor induk ayam tolaki yang dipelihara secara intensif di di Kandang Pembibitan Laboratorium Lapangan Fakultas Pertanian Universitas Halu Oleo Kendari. Umur induk sekitar 20 bulan. Sebelum telur ditetaskan terlebih dahulu ditimbang bobotnya dan diukur diameter panjang dan lebarnya untuk mengetahui indeks bentuk telurnya.

b. Peralatan

Peralatan yang digunakan untuk membuat mesin tetas sederhana sumber panas lisatrik maupun kombinasi listrik lampu minyak tanah yaitu, mistar, meteran, parang, pisau-cuter, sekap kayu dan gergaji. Peralatan yang digunakan sebagai perlengakapan dari kedua jenis mesin tetas yang digunakan adalah thermometer dan bak air/talang. Alat timbang untuk mengetahui bobot tetas anak ayam menggunakan timbangan O-Haus dengan kapasitas $2000 \mathrm{~g}$ dengan ketelitian $0,1 \mathrm{~g}$.

\section{Prosedur Penelitian}

a. Tahap persiapan penetasan meliputi: (a) stabilisasi suhu mesin tetas, (b) penyucihamaan mesin tetas 1 minggu sebelum penetasan, (c) perkawinan dilakukan dengan cara IB yang diawali dari penampungan semen dari 5 eor ayam jantan digunakan dalam penelitian, (d) pengumpulan telur, (e) pembersihan telur, (f) pemasukan telur ayng sudah dibersihkan ke dalam mesin tetas dan diletakan berdasarkan perlakuan, pada masing-masing ulangan dibatasi dengan sekat.

b. Tahap penetasan dan pengumpulan data: pengumpulan dan pencatatan data dilakukan pada saat sebelum telur mulai di masukan di dalam mesin, saat peneropongan dan saat telur menetas.

Pengoperasian lampu minyak pada mesin tetas kombinsi dilakukan dengan cara mematikan listrik dan digantikan dengan lampu minyak sebanyak tiga kali seminggu, sehingga selama tiga minggu lampu minyak dioperasikan sembilan kali. Setiap kali dioperasikan lampu minyak dinyalakan selama 3 jam. 


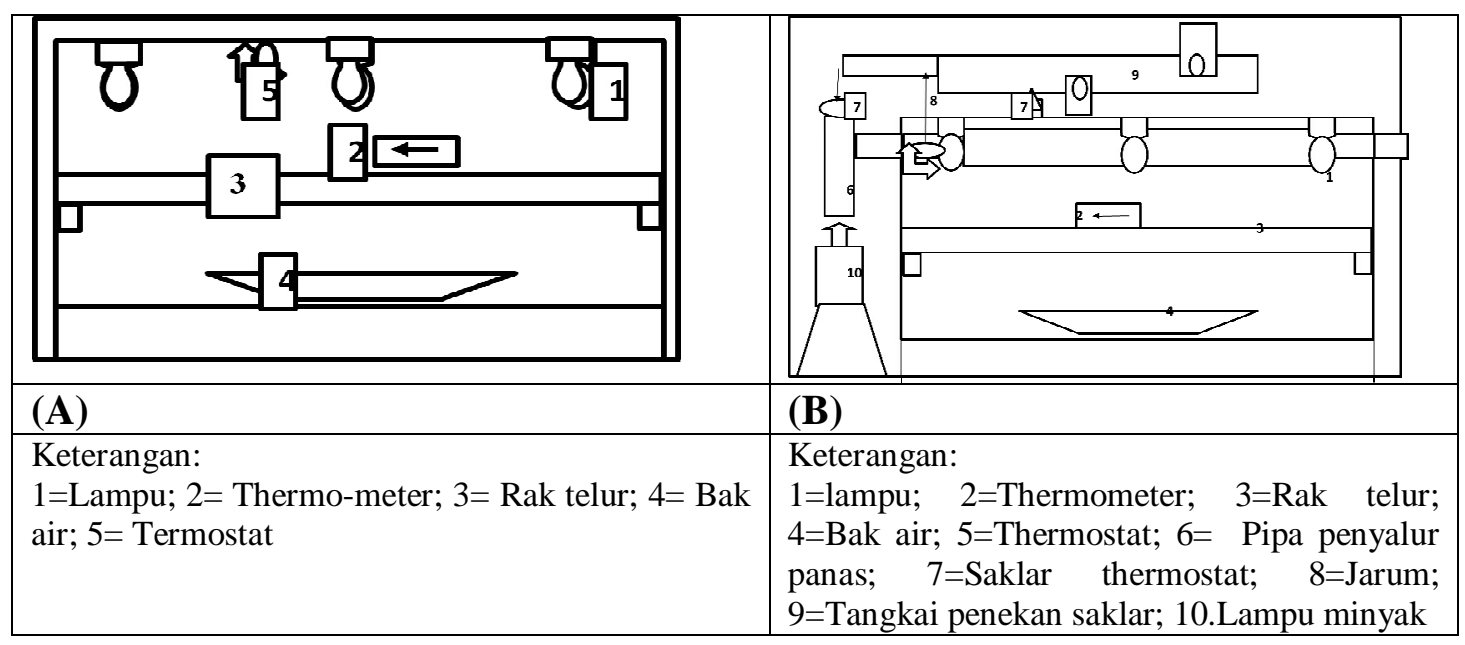

Gambar 1. Mesin Tetas dengan Sumber Panas yang Berbeda: (A) Mesin tetas sumber listrik (B) Mesin tetas sumber listrik dan minyak tanah

\section{Rancangan Penelitian}

Secara umum penelitian dilaksanakan 2 tahap, yaitu tahap persiapan penetasan dan pengumpulan data.

Telur tetas dibagi dalam dua perlakuan, yaitu mesin tetas dengan sumber panas listrik (PL) dan mesin tetas dengan sumber pemanas kombinasi antara listrik dan lampu minyak (PLM). Setiap perlakuan diulang enam kali, sehingga terdapat 12 unit percobaan. Setiap ulangan menggunakan 15 butir telur, sehingga telur tetas digunakan seluruhnya berjumlah 180 butir.

\section{Peubah yang diamati}

Peubah yang diamati dalam penelitian ini yaitu :

a. Fertilitas adalah persentase telur-telur yang bertunas dari sejumlah telur yang dieramkan, tanpa memperhatikan apakah telur-telur tersebut menetas atau tidak. Fertilitas diamati pada umur penetasan 7 hari yang dihitung dengan rumus :

Fertilitas dihitung dengan menggunakan rumus menurut North and Bell (1990) sebagai berikut:

$$
\text { Fertilitas }=\frac{\text { Jumlah telur fertil }}{\text { Jumlah telur ditetaskan }} \times 100 \%
$$

b. Daya hidup embrio (DHE) adalah persentase telur-telur yang fertil dari umur 7 hari penetasan sampai pada umur 14 hari penetasan, dihitung dengan rumus:

$$
\text { Fertilitas }=\frac{\sum \text { telur fertil yg hidup }}{\Sigma \text { telur fertil }} \times 100 \%
$$

c. Daya tetas adalah persentase telur-telur yang menetas dari jumlah telur yang fertil yang dihitung dengan rumus (Djannah, 1998):

$$
\text { Daya tetas }=\frac{\sum \text { telur fertil }}{\Sigma \text { tel }} \times 100 \%
$$

d. Umur menetas adalah umur telur mulai hari pertama penetasan sampai telur menetas. Persentase telur yang menetas pada hari ke $-20,21$, dan 22 hari dihitung dengan rumus :

Stelur menetas hari ke-

Umur menetas hari ke- $=\frac{}{\Sigma \text { telur menetas }} \times 100 \%$ 
Bobot tetas (g) adalah bobot badan anak ayam setelah menetas yang ditimbang setelah kering bulunya

\section{Analisis Data}

Data yang terkumpul dianalisis menggunakan uji t-student (Steel dan Torrie, 1995). Persamaan matematika uji tstudent sebagai berikut:

$$
t=\frac{X_{1}-X_{2}}{\operatorname{Sgab} \sqrt{ } 1 / n+\overline{1 / n}}
$$

Keterangan :

$\mathrm{X} 1=$ Rataan nilai pengamatan pada mesin tetas listrik

$\mathrm{X} 2=$ Rataan nilai pengamatan pada mesin tetas kombinasi

Sgab = Standar deviasi $(\mathrm{S})$ gabungan pada mesin tetas listrik dan mesin tetas kombinasi

$\mathrm{S}=\frac{\sum \mathrm{xi} 2-\left(\sum \mathrm{xi}\right) 2 \frac{}{\mathrm{n}}}{n-1}$

Pengolahan data penelitian menggunakan program Minitab Release V. 15 dengan kaidah pengambilan keputusan dari hasil analisis yakni: jika $P$-value $<0.05$, berarti peubah pada mesin tetas listrik berbeda nyata dengan mesin tetas kombinasi. Jika $P$-value $>0.05$, berarti peubah pada kedua mesin tetas tersebut tidak berbeda nyata.

\section{HASIL DAN PEMBAHASAN}

Hasil analisis data fertilitas, daya hidup embrio, daya tetas, lama menetas dan bobot tetas telur ayam tolaki pada mesin tetas sumber pada yang berbeda dapat dilihat pada Tabel 1 .

\section{a. Fertilitas}

Persentase fertilitas telur ayam tolaki pada mesin tetas sumber panas listrik (PL) dan mesin tetas kombinasi listrik dan lampu minyak (PLM) sebagaimana terlihat pada Tabel 1 menunjukkan bahwa secara umum rata-rata fertilitas telur ayam tolaki adalah $52,72 \%$. Fertilitas telur ayam tolaki yang dicapai pada penelitian ini lebih rendah dibandingkan dengan tertilitas ayam kampung yang dilaporkan Djafar (2001) yakni sebesar $65,18 \%$, fertilitas ayam kedu pebibit di Kabupaten Temanggung yaitu 74,24\% (Suryani $d k k$., 2012), fertilitas itik pada lama penyimpanan telur 1 hari, yaitu $91,67 \%$, lama penyimpanan 4 hari $83,33 \%$ dan lama penyimpanan 7 hari yaitu 72,29\% (Meliyati dkk., 2012),) fertilitas ayam petelur yang diinseminasi dengan semen pejantan ayam kampung dengan mengencerkan $\mathrm{NaCl}$ fisiologis 0,9 persen ditambah kuning telur $1 / 4$ bagian diperoleh hasil sebesar 70,83\% (Sujionohadi $d k k$., 2007).

Table 1. Fertilitas, Daya Hidup Embrio (DHE), Daya Tetas, Lama Menetas dan bobot Tetas Ayam Tolaki pada Mesin Tetas Sumber Panas yang Berbeda

\begin{tabular}{llccc}
\hline No & Parameter & $\begin{array}{c}\text { Mesin Tetas } \\
\text { Sumber Panas } \\
\text { Listik (PL) }\end{array}$ & $\begin{array}{c}\text { Mesin Tetas sumber } \\
\text { Panas Kombinasi } \\
(\text { PLM) }\end{array}$ & Rataan \\
\hline 1 & Fertilitas (\%) & 58,57 & 46,88 & 52,72 \\
2 & DHE (\%) & 96,67 & 89,58 & 93,13 \\
3 & Daya Tetas (\%) & 45,61 & 64,81 & 55,21 \\
4 & Lama Menetas (\%) & 21.05 & 21,09 & 21,07 \\
5 & Bobot Tetas (g) & 26,47 & 26,96 & 26,71 \\
\hline
\end{tabular}


Selain itu rendahnya fertilitas telur yang dicapai pada penelitian ini mungkin disebabkan oleh mesin tetas sederhana yang digunakan, sebagaimana dikemukakan oleh Suyatno (2005) bahwa kelemahan mesin tetas konvensional antara lain: (1) pemutaran dengan tangan masih kurang halus dan menimbulkan getaran yang dapat mengakibatkan kematian embrio ayam; (2) pemutaran telur tidak merata; (3) frekuensi pemutaran telur sangat terbatas, yaitu hanya tiga kali sehari (pagi, siang, dan sore); (4) suhu dan kelembaban kurang merata; serta (5) panas dalam mesin kurang stabil. Jumlah telur yang terkumpul selama penelitian juga terbatas, sehingga tidak memungkinkan adanya seleksi telur tetas, khususnya seleksi terhadap bentuk telur. Lestari dkk. (2013) menyatakan bahwa keberhasilan penetasan salah satunya ditentukan oleh kualitas telur. Telur tetas yang baik adalah telur yang berbentuk oval yang memiliki perbandingan garis tengah bagian yang lebar dan garis tengah bagian yang panjang 3:4 atau memiliki indeks bentuk telur 75 persen (Murtidjo, 1993). Menurut Yuwanta (2004) telur tetas yang normal memiliki indeks bentuk telur 70-75 persen. Bibit ayam tolaki jantan dan betina yang digunakan pada penelitian berumur sekitar 20 bulan. Rasyaf (1993) dalam Listiyowati dan Rospitasari (2004) menyatakan bahwa pengambilan telur tetas sebulan setelah dewasa kelamin (umur 9 bulan) dicapai fertilitas sebesar 85 sampai 95\%.

Rata-rata fertilitas telur ayam tolaki yang ditetaskan pada mesin tetas sumber panas listrik mencapai 58,57\%, sedangkan pada mesin tetas kombinasi hanya mencapai 46,88\%. Namun demikian, hasil uji-t menunjukkan bahwa fertilitas telur ayam tolaki pada kedua jenis mesin tetas tersebut tidak berbeda nyata $(\mathrm{P}>0,05)$.
Dalam penelitian ini perkawinan dilakukan melalui IB sebanyak dua kali seminggu. Kemungkinan telur-telur yang tidak fertil adalah telur yang diproduksi pada hari terakhir sebelum IB berikutnya, karena motilitas dan daya hidup sperma dalam saluran reproduksi betina semakin menurun. Hal ini sesuai pendapat Sutiyono dan Ondho (1991) bahwa setelah perkawinan, fertilitas telur berangsur menurun.Putra (2009) menyatakan bahwa faktor-faktor yang mepengaruhi fertilitas adalah motilitas sperma, ransum, hormon, lama penyinaran, umur ayam, produksi telur, musim, perbandingan jumlah jantan dan betina, serta lamanya jantan berada dalam kandang.

\section{b. Daya hidup embrio (DHE)}

DHE diketahui melalui peneropongan telur (candling) pada hari ke-14 umur penetasan, saat telur dibalik pada sore hari. Telur yang masih hidup pada 14 hari umur penetasan ditandai dengan bertambahnya jumlah dan ukuran akar-akar serabut pada telur, sedangkan telur yang mati ditandai adanya bintik dan benang darah merah yang mengelilingi telur. Persentase daya hidup embrio pada kedua jenis mesin tetas dapat dilihat pada Tabel 1. Berdasarkan Tabel 1 terlihat bahwa rata-rata DHE ayam tolaki pada penelitian ini adalah sebesar 93,13 persen. DHE yang diperoleh pada penelitian ini lebih tinggi daripada DHE ayam kampung hasil penelitian Solihati $d k k$. (2006), yakni sebesar $43,24 \%$ pada penyimpanan semen selama 1 jam, sedangkan pada penyimpanan semen 24 jam turun menjadi $21,68 \%$ dan pada penyimpanan 48 jam tinggal $10,32 \%$. Suryani $d k k$. (2012) melaporkan bahwa Rataan mortalitas embrio ayam kedu pebibit adalah $40,02 \%$, atau dengan kata lain DHE hanya sebesar $59,98 \%$. 
Semen ayam yang digunakan dalam penelitian ini langsung digunakan untuk IB, sehingga diperoleh DHE yang tinggi. Menurut Susilawati dan Hernawati (1992) bahwa semakin lama semen disimpan menyebabkan periode fertil semakin singkat, karena penyimpanan yang lebih lama akan semakin meningkatkan jumlah spermatozoa yang mati dan semakin banyak jumlah spermatozoa mati maka jumlah kematian spermatozoa hidup selama proses penyimpanan semakin meningkat, karena sperma yang mati akan menjadi racun bagi sperma yang masih hidup. Lama penyimpanan juga akan menyebabkan kerusakan membran plasma spermatozoa sehingga akan menurunkan motilitas dan pada akhirnya periode fertil juga lebih singkat.

Tingginya DHE kemungkinan juga besar disebabkan penanganan telur tetas selama proses penetasan dilakukan secara hati-hati dan penanganan telur pada saat pembalikan tidak terlalu lama, sehingga suhu dalam mesin tetas tetap stabil.Hal ini sesuai dengan pendapat Tullet (1990) bahwa keberhasilan penetasan tergantung dari suhu, kelembaban, frekuensi pemutaran telur, ventilasi dan kebersihan telur. Demikian pula halnya dengan Iswanto (2005) yang menyatakan bahwa kondisi suhu dalam mesin tetas yang tidak merata, kemungkinan dapat menimbulkan kematian pada calon DOC. Lebih lajut dijelaskan bahwa pembalikan telur dalam mesin tetas sebaiknya dilakukan tiga kali sehari yakni pada pagi, siang, sore hari. Saat membalik telur, lakukan secara perlahan, usahakan tidak sampai tersentak supaya telur tidak retak atau pecah dan isinya tidak terguncang.

Berdasarkan uji t-student diketahui bahwa mesin tetas sederhana yang menggunakan sumber panas berbeda dalam penelitian ini tidak berpengaruh nyata $(\mathrm{P}>0,05)$ terhadap DHE. DHE pada mesin tetas sumber panas listrik adalah 96,67\%, sedangkan pada mesin tetas kombinasi sebesar 89,58\%. Kematian embrio selama penelitian dapat terjadi karena kualitas telur yang ditetaskan dapat pula disebabkan oleh mesin tetas yang digunakan. Menurut Tullett dan Burton (1987) bahwa penghambatan pertumbuhan embrio terjadi karena berhubungan dengan hal-hal berikut: (1) pengurangan pertukaran gas, kegagalan chorioallantois menjadi garis permukaan yang lengkap pada membran kerabang dalam; (2) pengurangan perluasan daerah vaceculosa, pembatasan pengambilan nutrien oleh embrio, dan (3) kegagalan embrio dalam menggunakan sisa albumen. Lebih lanjut Suprijatna $d k k$. (2005) menambahkan bahwa apabila induk mengalami defisiensi mineral maka berdampak pada fertilitas dari telur yang ditetaskan, hal ini juga berpengaruh pada perkembangan embrio.

\section{Daya Tetas}

Daya tetas ditentukan berdasarkan jumlah telur tetas yang menetas dari sejumlah telur-telur tetas yang tertunas atau fertil (Djannah, 1998). Visualisasi anak ayam yang menetas pada mesin tetas dengan sumber panas yang berbeda dapat dilihat pada Gambar 2. Sementara itu daya tetas telur ayam tolaki pada mesin tetas sumber panas yang berbeda dapat dilihat pada Tabel 1. Berdasarkan Tabel 1 terlihat bahwa ratan daya tetas telur ayam tolaki adalah 55,21\%. Hasil penelitian ini lebih rendah dibandingkan dengan hasil 


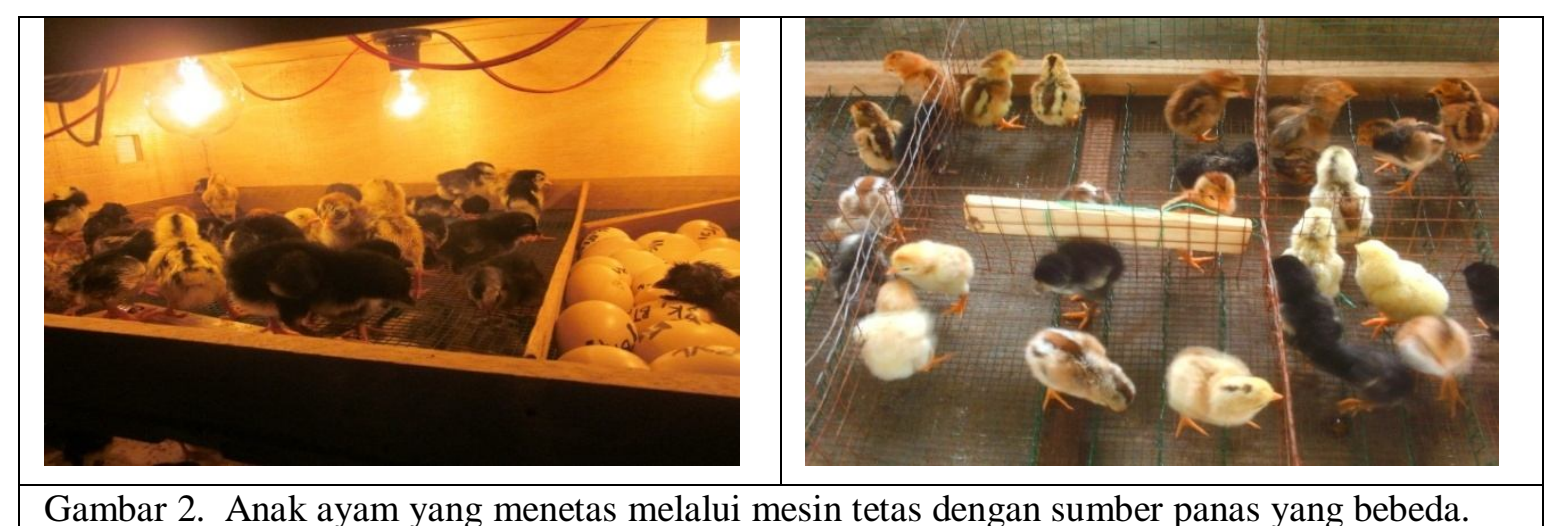

penelitian Djafar (2001) yang mendapatkan daya tetas ayam kampung sebesar $75,26 \%$. Demikian pula Irianty $d k k$. (2005) melaporkan bahwa dengan penambahan vitamin E sebanyak $20 \mathrm{mg} / \mathrm{kg}$ pakan pada ayam kampung menghasilkan daya tetas sebesar $73,31 \%$ dan $30 \mathrm{mg} / \mathrm{kg}$ pakan menghasilkan daya tetas $74,11 \%$. Zakarian (2010) melaporkan bahwa rataan daya tetas telur telur ayam kampung adalah71,67\%, bahkan jauh lebih rendah dari daya tetas telur itik mallard yang mencapai $84,18 \%$ 89,10\% (Romjali et.al., 2006).

Rataan daya tetas telur itik khaki campbell pada lama akan semakin meningkatkan jumlah spermatozoa yang mati dan semakin banyak jumlah spermatozoa mati maka jumlah kematian spermatozoa hidup selama proses penyimpanan semakin meningkat, karena sperma yang mati akan menjadi racun bagi sperma yang masih hidup. Lama penyimpanan juga akan menyebabkan kerusakan membran plasma spermatozoa sehingga akan menurunkan motilitas dan pada akhirnya periode fertil juga lebih singkat.

Tingginya DHE kemungkinan juga besar disebabkan penanganan telur tetas selama proses penetasan dilakukan secara hati-hati dan penanganan telur pada saat pembalikan tidak terlalu lama, sehingga suhu dalam mesin tetas tetap stabil.Hal ini sesuai dengan pendapat Tullet (1990) bahwa keberhasilan penetasan tergantung dari suhu, kelembaban, frekuensi pemutaran telur, ventilasi dan kebersihan telur. Demikian pula halnya dengan Iswanto (2005) yang menyatakan bahwa kondisi suhu dalam mesin tetas yang tidak merata, kemungkinan dapat menimbulkan kematian pada calon DOC. Lebih lajut dijelaskan bahwa pembalikan telur dalam mesin tetas sebaiknya dilakukan tiga kali sehari yakni pada pagi, siang, sore hari. Saat membalik telur, lakukan secara perlahan, usahakan tidak sampai tersentak supaya telur tidak retak atau pecah dan isinya tidak terguncang.

Berdasarkan uji t-student diketahui bahwa mesin tetas sederhana yang menggunakan sumber panas berbeda dalam penelitian ini tidak berpengaruh nyata $(\mathrm{P}>0,05)$ terhadap DHE. DHE pada mesin tetas sumber panas listrik adalah $96,67 \%$, sedangkan pada mesin tetas kombinasi sebesar $89,58 \%$. Kematian embrio selama penelitian dapat terjadi karena kualitas telur yang ditetaskan dapat pula disebabkan oleh mesin tetas yang digunakan. Menurut Tullett dan Burton (1987) bahwa penghambatan pertumbuhan embrio terjadi karena berhubungan dengan hal-hal berikut: (1) pengurangan pertukaran gas, kegagalan chorioallantois menjadi garis permukaan yang lengkap pada membran kerabang dalam; 
(2) pengurangan perluasan daerah vaceculosa, pembatasan pengambilan nutrien oleh embrio, dan (3) kegagalan embrio dalam menggunakan sisa albumen. Lebih lanjut Suprijatna dkk. (2005) menambahkan bahwa apabila induk mengalami defisiensi mineral maka berdampak pada fertilitas dari telur yang ditetaskan, hal ini juga berpengaruh pada perkembangan embrio.

\section{Daya Tetas}

Daya tetas ditentukan berdasarkan jumlah telur tetas yang menetas dari sejumlah telur-telur tetas yang tertunas atau fertil (Djannah, 1998). Visualisasi anak ayam yang menetas pada mesin tetas dengan sumber panas yang berbeda dapat dilihat pada Gambar 2. Sementara itu daya tetas telur ayam tolaki pada mesin tetas sumber panas yang berbeda dapat dilihat pada Tabel 1. Berdasarkan Tabel 1 terlihat bahwa ratan daya tetas telur ayam tolaki adalah 55,21\%. Hasil penelitian ini lebih rendah dibandingkan dengan hasil penelitian Djafar (2001) yang mendapatkan daya tetas ayam kampung sebesar 75,26\%. Demikian pula Irianty $d k k$. (2005) melaporkan bahwa dengan penambahan vitamin E sebanyak $20 \mathrm{mg} / \mathrm{kg}$ pakan pada ayam kampung menghasilkan daya tetas sebesar $73,31 \%$ dan $30 \mathrm{mg} / \mathrm{kg}$ pakan menghasilkan daya tetas $74,11 \%$. Zakarian (2010) melaporkan bahwa rataan daya tetas telur telur ayam kampung adalah71,67\%, bahkan jauh lebih rendah dari daya tetas telur itik mallard yang mencapai $84,18 \%$ 89,10\% (Romjali et.al., 2006).

Rataan daya tetas telur itik khaki campbell pada Bobot tetas telur ayam tolaki yang ditetaskan pada mesin tetas dengan sumber panas yang berebeda disajikan pada Tabel 1. Berdasarkan data pada Tabel 1 terlihat bahwa rata-rata bobot tetas ayam tolaki adalah 26,71 g. Bobot tetas pada hasil penelitian ini lebih rendah dibandingkan dengan hasil penelitian Irianty $d k k$. (2005) bahwa dengan penambahan vitamin E sebanyak $20 \mathrm{mg} / \mathrm{kg}$ pakan pada ayam kampung akan menghasilkan bobot tetas sebesar 28,24 g dan $30 \mathrm{mg} / \mathrm{kg}$ pakan akan menghasilkan bobot tetas $29,36 \mathrm{~g}$.

Rendahnya bobot tetas telur ayam tolaki pada penelitian ini diduga disebabkan ayam tolaki memiliki ukur telur dan postur tubuh yang kecil dan ramping bila dibandingkan dengan ayam kampung. Hal ini sesuai dengan Nafiu $d k k$. (2009) yang melaporkan bahwa selain postur tubuh yang kecil dan ramping, ayam tolaki memiliki telur yang relatif kecil dengan rata-rata bobot $35.55 \mathrm{~g}$ atau berkisar 27.00$41.55 \mathrm{~g}$, lebih ringan dibanding ayam kampung yang mencapai $35-45 \mathrm{~g}$ (Mansjoer, 2003). Nataamijaya et al. (1989), melaporkan bahwa berat tetas anak ayam buras yang sumber telurnya yang berasal dari induk yang relatif sama adalah sebesar 32,03 g, sedangkan Mugiyono et al. (1989) melaporkan bahwa berat tetas ayam buras yang sumber telur yang berasal dari induk yang relatif sama sebesar 31,17 g, dan Zakarian (2010) melaporkan bobot tetas ayam kampung adalah 31,82 $\mathrm{g}$.

Rata-rata bobot tetas ayam tolaki pada mesin tetas sumber panas listrik sebesar 26,47 g, sedangkan pada mesin tetas sumber panas kombinasi adalah 26,96 g. Berdasarkan hasil uji t-student diketahui bahwa bobot tetas telur ayam tolaki pada mesin tetas dengan sumber panas listrik tidak berbeda nyata $(\mathrm{P}>0,05)$ dengan mesin tetas sumber panas kombinasi.

Penempatan telur pada kedua mesin tetas dilakukan secara acak, sehingga bobot tetas pada mesin tetas listrik dan mesin tetas kombinasi tidak jauh berbeda. Disamping itu, bobot tetas dipengaruhi oleh bobot telur. Wiharto (1988) 
menyatakan bahwa penetasan dengan bobot telur seragam akan memberikan hasil yang baik karena anak-anak unggas yang menetas nantinya juga memiliki bobot yang seragam. Telur harus seragam bentuk, warna dan bobotnya. Selanjutnya menurut Rasyaf (1989) dalam Ilmi (2005) bahwa ada hubungan yang positif antara bobot telur dengan bobot awal anak ayam yang menetas pada umur sehari. Djannah (1998) dalam Ilmi (2005) bahwa bobot dan besarnya telur merupakan suatu karakter performans yang mewaris dari tetua ke anak ayam, karakter itu berbeda setiap bangsa, varietas dan strain ayam.

\section{c. Lama Menetas}

Telur ayam kampung umumnya akan menetas setelah dierami selama 21 hari. Rata-rata lama menetas telur ayam tolaki pada mesin tetas dengan sumber panas yang berbeda disajikan pada Gambar 3.

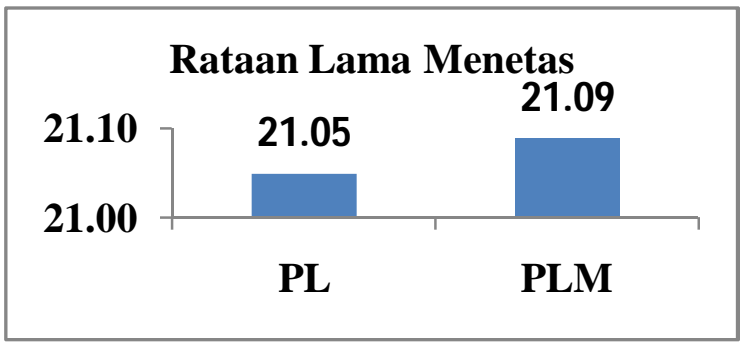

Gambar 3. Rataan Lama Menetas Ayam Tolaki

Gambar 3 menunjukkan bahwa ratarata lama menetas telur ayam tolaki adalah
21,07 hari. Hasil penelitian ini sesuai dengan Nuryati $d k k$. (2000) bahwa pada umur dua puluh hari kantung kuning telur sudah masuk seluruh ke dalam rongga perut, embrio hampir menempati seluruh rongga di dalam telur kecuali kantung udara, pada umur 21 hari ayam sudah membuka kerabangnya walaupun belum seluruhnya dan memerlukan waktu 12 sampai 18 jam untuk keluar dari kerabang.

Lama menetas telur ayam tolaki yang ditetaskan pada mesin tetas sumber panas listrik adalah 21.05 hari dan sumber panas kombinasi listrik dan lampu minyak adalah 21,09 hari. Berdasarkan hasil uji t diketahui bahwa umur menetas telur pada kedua jenis mesin tetas tersebut tidak berbeda nyata $(\mathrm{P}>0.05)$. Hal ini dikarenakan umur dan bobot telur yang digunakan dianggap seragam. Umur telur berkisar 1-7 hari sedangkan bobot telur 38.71-43.02 g. Hal ini sesuai dengan pendapat Wiharto (1988) bahwa keseragaman bobot telur akan berpengaruh terhadap lama pengeraman dan masa penetasan. Dalam penelitian ini telur ayam tolaki menetas pada umur penetasan 20, 21 dan 22 hari. Persentase telur yang menetas pada umur penetasan 20, 21 dan 22 hari dari seluruh telur yang menetas pada mesin tetas PL dan mesin tetas PLM disajikan pada Tabel 3

Tabel 3. Persentase telur yang menetas pada umur berbeda dari seluruh telur yang menetas

\begin{tabular}{llllllll}
\hline \multirow{2}{*}{$\begin{array}{l}\text { Mesin } \\
\text { tetas }\end{array}$} & \multicolumn{9}{l}{ Umur menetas (hari) } & \multicolumn{3}{l}{2} & \\
\cline { 2 - 7 } & 20 & \multicolumn{3}{l}{21} & \multicolumn{3}{l}{ Total } \\
& $\begin{array}{l}\text { Jumlah } \\
\text { menetas }\end{array}$ & $(\%)$ & $\begin{array}{l}\text { Jumlah } \\
\text { menetas }\end{array}$ & $(\%)$ & $\begin{array}{l}\text { Jumlah } \\
\text { menetas }\end{array}$ & $(\%)$ & \\
\hline PL & - & - & 26 & 89,66 & 3 & 10,34 & 100 \\
\hline PML & 1 & 4,17 & 20 & 83,33 & 3 & 12,5 & 100 \\
\hline Total & 1 & 4,17 & 46 & 172,99 & 6 & 22,84 & 200 \\
\hline Rerata & 1 & 4,17 & 23 & 86,50 & 3 & 11,42 & 100 \\
\hline
\end{tabular}


Tingginya telur yang menetas pada umur penetasan 21 hari pada kedua jenis mesin tetas pada penelitian ini, karena suhu dan kelembaban inkubator stabil dan embrio dapat berkembang dengan normal. Hal ini sesuai dengan pendapat Jasa (2006) bahwa suhu embrio harus sesuai dengan kondisi pada proses penetasan alami menggunakan induk. Lebih lanjut dijelaskan bahwa agar embrio dapat berkembang dengan baik maka suhu di dalam ruang penetasan diatur dengan kisaran suhu $95-104^{\circ} \mathrm{F}$ sehingga menjamin embrio mendapatkan suhu yang ideal untuk perkembangan yang normal.

\section{KESIMPULAN DAN SARAN}

Fertilitas, daya hidup embrio, daya tetas, umur menetas dan bobot tetas telur ayam tolaki yang ditetaskan pada mesin tetas dengan sumber panas listrik (PL) tidak berbeda nyata $(\mathrm{P}>0,05)$, dengan yang ditetaskan pada mesin tetas sumber panas kombinasi listrik dan lampu minyak (PLM). Namun demikian secara kuantititas rataan daya tetas pada mesin PLM $(64,81 \%)$ cenderung lebih tinggi dibandingkan mesin tetas PL $(45,61 \%)$.

Berdasarkan hasil penelitian disarankan kepada peternak terutama di daerah pedesaan untuk menggunakan mesin tetas dengan sumber panas kombinasi listrik dan lampu minyak.

\section{UCAPAN TERIMA KASIH}

Tim penulis menyampaikan terima kasih dan penghargaan yang sebesarbesarnya kepada Dekan dan Kepala Laboratorium Lapangan Fakultas Peternakan UHO yang memberikan izin untuk menggunakan seluruh fasilitas yang diperlukan dalam peneltian ini. Kami juga ucapkan terima kasih kepada Rusli Badaruddin, S.Pt., M.Si. dan Hazizi, S.Pt. yang turut membantu dalam pelaksanaan penelitian.

\section{DAFTAR PUSTAKA}

Christensen, L. V., 1991. Diluents, dilution and strorage of poultry semen for six hour. Proceeding First Internasional Symposium on the Artificial Insemination of Poultry Science Asdsociation, Inc. USA.

Djannah, D., 1998. Beternak Ayam. Yasaguna. Surabaya.

Ilmi, I., 2005. Pengaruh bentuk dan umur telur terhadap daya tetas dan proporsi jenis kelamin ayam arab. Universitas Haluoleo. Kendari.

Iriyanti, N., Zuprizal, T. Yuwanta, dan S. Keman. 2005. Penggunaan vitamin $E$ dalan pakan terhadap fertilitas, daya tetas, dan bobot tetas telur ayam kampung. Fakultas peternakan Universitas Gajah Mada. Yogyakarta.

Iswanto, H., 2005. Ayam Kampung Pedaging. Agromedia Pustaka. Jakarta.

Jasa, L., $2006 . \quad$ Pemanfaatan Mikrokontroler Atmega 163 Pada Prototipe Mesin Penetasan Telur Ayam. Jurnal Teknologi Elektro Vol 5 (1):30-36.

Kartasudjana, R., 2001. Penetasan Telur. Proyek Pengembangan Sistem dan Standar Pengelolaan Smkdirektorat Pendidikan Menengah Kejuruan. Departemen Pendidikan Nasional. Jakarta.

Lestari, E., Ismoyowati, dan Sukardi. 2013. Korelasi antara bobot telur dengan bobot tetas dan perbedaan susut bobot pada telur entok (Cairrina moschata) dan itik (Anas plathyrhinchos). Jurnal Ilmiah Peternakan 1(1):163-169.

Listiyowati, E., dan Rospitasari, K., 2004. Unggas tata laksana budidaya 
secara komersial. Penebar swadaya. Jakarta.

Mansjoer, S. 2003. Potensi ayam buras di Indonesia. Makala semiloka pengkajian pengembangan produksi bibit ayam Buras dan Itik. Cisrua Bogor. Tanggal 11 - 12 Desember 2003.

Meliyati, N., K., Nova dan D. Septinova. 2012. Pengaruh umur telur tetas itik mojosari dengan penetasan kombinasi terhadap fertilitas dan daya tetas. Skripsi. Jurusan Peternakan Fakultas Pertanian Universitas Lampung.

Mugiyono, S., Sukardi dan E. Tugiyanti, 1989. Perbandingan pemeliharan ayam buras secara tradisional dan semi intensif. Proc. Seminar Nasional tentang Unggas Lokal. Fakultas Peternakan Universitas Diponegoro, Semarang. Hal. 65-67.

Murtidjo, B., 1993. Mengelola Itik. Penerbit Kanisius. Yogyakarta.

Nafiu, L.O. dan M. Rusdin. 2007. Studi potensi dan keragaman ayam lokal di Sulawesi Tenggara. Laporan Penelitian. Lembaga Penelitian unhalu. Unpublished. Kendari.

Nafiu, L. O., T. Saili, M. Rusdin, A.S. Aku dan Y. Taufik. 2009. Pelestarian dan Pengembangan Ayam Tolaki sebagai Plasma Nutfah Asli Sulawesi Tenggara. Lembaga Penelitian Universitas Haluoleo. Kendari.

Nataamijaya, A.G., H. Resnawati, T. Antawijaya, I. Barchia dan D. Zainuddin, 1989. Produktivitas ayam buras di dataran tinggi dan dataran rendah. Balitnak, Ciawi-Bogor

Ningtyas, M.S., Ismoyowati dan I. H. Sulistyawan. 2013. Pengaruh temperatur terhadap daya tetas dan hasil tetas telur itik
(Anasplathyrinchos. Jurnal Ilmiah Peternakan 1(1):347-352.

North, M. O. dan D. D. Bell., 1990. Commercial Chicken Manual. $4^{\text {th }}$ Ed. Avi Publishing Company Inc. West Port, California.

Nurhayati, T., Sutarto, dan Karim, M.,2000. Sukses Menetaskan Telur. Penebar Swadaya. Cianjur.

Putra. Z., 2009. Fertilitas dan daya tetas.PSK Unggas Kelas Dua Untuk Siswa/I SPP-SPMAN Saree Provinsi Aceh. Banda Aceh.

Rasyaf, M., 1989. Pengelolaan Penetasan. Penerbit Swadaya. Jakarta.

Riyanto dan Anthonius, 2001. Sukses Menetaskan Telur Ayam. Agromedia Pustaka. Jakarta.

Romjali, E., A.L. Lambio, E. S. Luis, N.P. Roxas and A.A. Barion. 2006. fertility and hatchability of eggs on mallard ducks (Anas platyrhynchos L.) of different plumage pattern under different feeding regimes. Pros. Seminar Nasional Teknologi Peternakan dan Veteriner: 674-679.

Solihati, N., Idi, R., Setiawan, R., Asmara, I.Y., Bayu, I., Sujana. 2006. Pengaruh lama penyimpanan semen cair ayam buras pada suhu 5 ${ }^{\circ} \mathrm{C}$ terhadap periode fertile dan fertilitas sperma. Fakultas Peternakan Universitas Padjadjaran. Bandung.

Steel RGD, dan Torrie JH. 1995. Prinsip dan Prosedur Statistika. Suatu Pendekatan Biometrik. Ed ke-2. Penerbit PT. Gramedia Pustaka Utama, Jakarta.

Subiharta dan Yuwana, D.M., 2012. Pengaruh penggunaan bahan tempat air dan letak telur di dalam mesin tetas yang perpemanas listrik pada penetasan itik tegal. Seminar 
Nasional Kedaulatan Pangan dan Energi 1-7.

Sujionohadi, K dan Setiawan A., 2007. Ayam Kampung Petelur. Penebar Swadaya (edisi revisi). Jakarta.

Susilawati, S. dan T. Hermawati. 1992. Penggunann Pengencer Larutan Buah untuk Menyimpan Semen Domba. Media Kedokteran Hewan. Vol.3. No.3.

Suprijatna, E., Atmomarsono, U., Kartasudjana, R., 2005. Ilmu Dasar Ternak Unggas. Penebar swadaya. Jakarta.

Suryani, N., N. Suthama dan H. I. Wahyuni. 2012. Fertilitas telur dan mortalitas embrio ayam kedu pebibit yang diberi ransum dengan peningkatan nutrien dan tambahan Sacharomyces cerevisiae. Animal Agricultural Journal, Vol. 1. (1): 389 $-404$.

Sutiyono dan Ondho, Y. S., 1991. Fertilitas spermatozoa pada alat kelamin betina. Media 16 (4) : 9-11.

Suyatno. 2005. Otomatisasi mesin tet as untuk meingka tkan produksi DOC (Day Old Chick) ayam lurik dan efisiensi usaha. Junal DEDIKASI Volume 3: 17-25.

Tullett, S. G., 1990. Science dan the art of incubation. Pult. Sci. $69: 1-15$

Tullett, S. G. dan F.G. Burton, 1987. Effect of two gas mixtures on growth of the domestic fowl embryo from days 14 through 17 of incubation. J. Exp. Zool. Suppl. 1 : 347-350.

Widyaningrum, A.E., E. Sudjarwo dan Achmanu. 2012. Pengaruhjenis bahan dan frekuensi penyemprotan terhadap daya tetas, bobot tetas, dan dead embryo telur itik khaki campbell. Skripsi. Fakultas Peternakan. Universitas Brawijaya, Malang

Wiharto, 1988. Petunjuk Pembuatan Mesin Penetas. Penerbit Lembaga Penerbitan Universitas Brawijaya. Malang.

Yuwanta, T., 2004. Dasar Ternak Unggas. Penerbit Kanisius. Yogyakarta.

Zakaria, M.A.S., 2010. Pengaruh lama penyimpanan telur ayam buras terhadap fertilitas, daya tetas telur dan berat tetas. Jurnal Agrisistem Vol. $6(2): 97-102$ 